(16) The receptionist can also help by fixing future appointments for a time when the clinic or surgery is quietest, and by putting the appointment time and any other instructions in writing.

\section{Mental handicap}

Most of the points that apply to dysphasic patients can usefully be remembered when dealing with the mentally handicapped, especially the following.
(1) Use simple sentences, but do not "talk down."

(2) Put instructions in writing; there will usually be someone in the patient's environment who can read.

(3) Both truculence and shyness are often due to being in an unfamiliar environment, so putting the patient at ease achieves better communication.

(4) There is an increasing use of sign language among the mentally handicapped attending centres and in institutions. If your patient starts making strange gestures he may well be trying to communicate.

\title{
Pollution and People
}

\section{Contamination of food: mycotoxins and metals}

\author{
DAPHNE GLOAG
}

Contamination of food is both more and less of a problem than in the past. There is clearly more pollution by extraneous substances-notably heavy metals and residues of agricultural chemicals-but at the same time better methods of storage and preservation have reduced the prevalence of toxins from natural sources. In the former case too the extensive surveillance ${ }^{1}$ of foodstuffs by more refined analytical techniques is tending to raise standards. The fact that the incidence of gastric cancer is falling in Western countries possibly reflects a reduction in the carcinogens, natural ${ }^{2}$ and otherwise, that are ingested in food. ${ }^{3}$ But the very existence now of more sensitive methods for detecting contaminants makes for more awareness of the problems-and raises questions about thresholds of activity. Of the many possible topics, I discuss mycotoxins, mercury, and cadmium in this article (having already touched on lead in food -3 January, p 41); in the next one I will take a brief look at some chemicals.

\section{Mycotoxins}

The convulsions and hallucinations, dancing mania, and finally gangrene of "St Anthony's fire" or ergotism are probably the most terrifying manifestations of the contamination of food. It was a common epidemic disease in the tenth and eleventh centuries and occurred in Provence as recently as $1951^{4}$; it was due to alkaloids-of which LSD is one-produced by the ergot fungus, Claviceps purpura, on rye. Ergotism is of interest as the earliest known disease produced by fungal toxins (the connection was recognised in the $1850 \mathrm{~s}$ ). A few local outbreaks of other mycotoxicoses were reported earlier this century, ${ }^{5}$ but the subject really came to notice in Britain when in 1961 hundreds of thousands of turkey poults and ducklings died after receiving feeds containing Brazilian groundnut meal. Soon the toxin was isolated and named aflatoxin after the fungus Aspergillus flavus, and was found to be carcinogenic in rats. ${ }^{6}$ Its toxicity and

British Medical Journal, London WC1H 9JR

DAPHNE GLOAG, MA, staff eaitor carcinogenicity for the liver and sometimes other organs have since been shown in a wide range of animals. ${ }^{7-9}$ There is less direct evidence that aflatoxin is toxic and carcinogenic in man. ${ }^{5} 9$

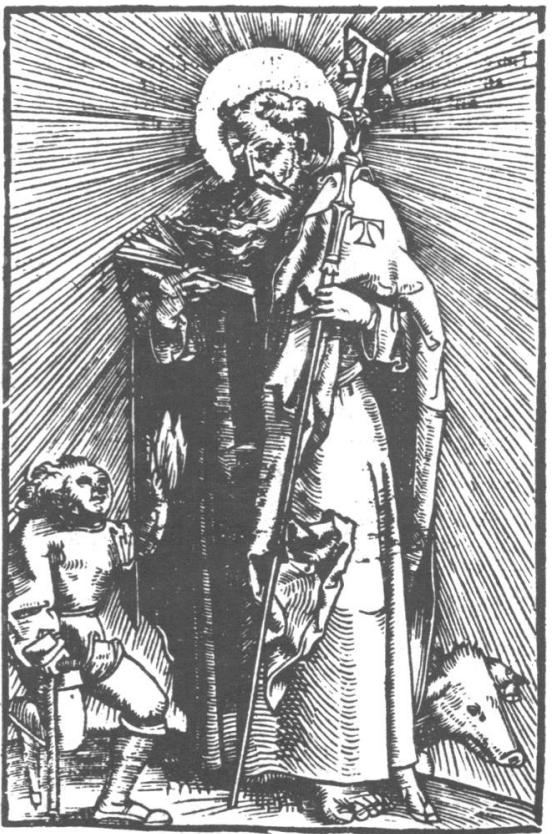

Woodcut of St Anthony with a victim of "St Anthony's fire" (ergotism); the "fire" refers to the tingling in the limbs. From H von Gersdorf, Feldbuch der Wundtartzney, Frankfurt: 1551. Reproduced by courtesy of the Wellcome Trustees.

Aflatoxin is the most widely studied mycotoxin but several others are known to cause disease in man. ${ }^{5}{ }^{9}$ Fungi can grow on almost any plant product so there is great scope for contamination of food by mycotoxins given appropriate conditions. The strains of the two Aspergillus species producing aflatoxin are ubiquitous; but it needs hot, humid conditions during crop growth, harvesting, or storage for its production. Ochratoxin (a common contaminant of cereals and many other foods) can be produced by some species of Penicillium at 
temperatures as low as $5^{\circ} \mathrm{C} .{ }^{9}$ Since they are often present in animal feeds mycotoxins can indirectly contaminate human food-meat and dairy products - as well as directly; and they are not destroyed by cooking or the usual processing. Now that sensitive analytical methods have been developed low-level contamination is seen to be fairly common even in Britain. ${ }^{10}$ But does it matter ? The answer is not yet clear, though common ill effects are improbable; and as usual we must look first at the evidence relating to grosser contamination.

\section{AFLATOXIN AND HUMAN DISEASE}

Acute liver disease has been associated with food contaminated with aflatoxin. ${ }^{9}$ Cause and effect have not been proved in the reported cases but the outbreaks in domestic animals as well as experimental evidence support a link. The largest outbreak was in western India in 1974, when nearly 200 villages were affected after unseasonal rains had drenched the maize crops and the staple food became heavily contaminated with Aspergillus flavus, high concentrations of aflatoxin being found in sampled grains. ${ }^{11}$ The victims (twice as many men as women) were thought to have had 2-6 $\mathrm{mg}$ of aflatoxin a day for some weeks; and though some people claimed to have been affected without having eaten the maize ${ }^{9}$ there were many strands of circumstantial evidence to incriminate it. Another condition thought to be sometimes linked with aflatoxin is Reye's disease, but case-control studies have not been done. ${ }^{9}$

The worst aflatoxin contamination occurs in populations in parts of Africa and Thailand with high rates of primary liver cancer; and the highest known intake, in Mozambique (a mean of over $15 \mu \mathrm{g}$ a day), is in the area with the highest known liver cancer rate in the world. ${ }^{12}$ Comparison with other areas suggests a significant correlation between aflatoxin in the diet and liver cancer-the incidence of the disease (again much more common in men) appearing proportional to the logarithm of the aflatoxin intake. The WHO report concludes that aflatoxin in man may increase the risk of liver cancer, that the risk depends on the amount ingested, and that reducing the daily intake could be expected to reduce the risk. ${ }^{9}$ But no one knows whether the risk extends down to the lowest levels of contamination, or whether some cases of liver cancer in the developed countries could be due to aflatoxin. Clearly people living on narrow diets of contaminated staple foods are chiefly at risk. Hepatitis B infection, of course, is prevalent in countries where liver cancer is most common and this (and other factors) may play a part-possibly aflatoxin and hepatitis B virus are cocarcinogens. ${ }^{9}$

\section{MYCOTOXINS IN OUR FOOD}

The recent survey of mycotoxins in Britain ${ }^{10}$ was reasonably reassuring-but perhaps less so than it would have been a few years ago, since the highly sensitive methods now show low-level contamination in a wide range of foods-notably cereals and cereal products, dairy products, nuts, pulses, and dried fruit. As infant foods need the most purity cereals and milk are of special interest. Cereals are particularly liable to fungal growth but mycotoxins show low

\section{Mercury}

Mercury is found in trace quantities in all parts of the environment. It comes both from natural sources and from industrial use (the production of chlorine and alkalis using more than any other activity); but some agricultural and other uses have declined or ceased. The Control of Pollution Act 1974 empowers water authorities and local authorities to control the discharge of toxic materials, including mercury, into rivers and the sea and the disposal of waste on land. Food is the main source of mercury for the general population, and the Working Party on the Monitoring of Food Stuffs for Heavy Metals carries out surveillance. The usual intake of methylmercury in the British diet is 2-5 $\mu \mathrm{g}$ a day, around one-tenth of the FAO/WHO limit. ${ }^{13}$ concentrations in the good-quality cereals eaten in developed countries. ${ }^{10}$ Milk may contain the metabolite aflatoxin $M_{1}$; but this is at a concentration estimated at about 300 times less than that of aflatoxin $B_{1}$ in the cattle feed" (and in general aflatoxins in animal products are less than a thousandth of the toxin ingested by the animal ${ }^{13}$ ). Furthermore, drying, pasteurisation, and sterilisation considerably reduce the aflatoxin $M_{1}$ concentrations in milk.

All in all, there seems to be no great hazard from mycotoxins in the developed countries; but consumption of even small quantities of possibly powerful carcinogens seems undesirableuntil we know whether there is a threshold of activity, and whether in man they are carcinogens in their own right or cocarcinogens acting with other factors, and until "safe levels" are defined. Stricter standards for imports are being discussed; but these would often mean even lower standards of living for the poor populations of the exporting countries-including the need to eat only the lowest-quality produce themselves. Improved husbandry, storage conditions, etc, are the ultimate answer but this is more easily said than done in many places. Selection and refining processes remove much mycotoxin; but sampling of produce and products poses problems because mycotoxins may be confined to occasional grains or one or two nuts in a kilogram, and contaminated nuts may have no obvious mould on the shell. Methods of chemical decontamination are suitable for animal foodstuffs ${ }^{13}$ and would work out cheaper than throwing away whole batches.

$\mathrm{Up}$ to $30 \mu \mathrm{g} / \mathrm{kg}$ of aflatoxin is allowed in food supplements for malnourished children by the United Nations Protein Advisory Group, ${ }^{13}$ immediate malnutrition being a greater threat than speculative long-term risks. This is an uncomfortable reflection of the inequalities of life; for, by contrast, a spokesman for the US Food and Drug Administration said, "Mycotoxins may be one of the most significant pollutants known to man and may be the cause of many diseases in man of unknown aetiology. The FDA will err on the side of ensuring safety for the consumer." 14 Rather than press immediately for even stricter formal standards we should perhaps attend more to three aspects of food quality. People do not use mouldy food, but mycotoxins may spread from the mould some way into the food (for instance, a large consignment of flour that was rained on and sent for checking was found to have high concentrations of ochratoxin even where there was no obvious mould). People need to be told that just paring the mould off a piece of cheese, say, is not enough. Secondly, immigrants may continue with food customs that are unsuited to a different climate and these may reed scrutiny. Thirdly, "health foods" may escape unnatural preservatives and residues of other chemicals, including fungicides, only to acquire toxinogenic moulds when stored under imperfect conditions. ${ }^{13}$

\section{Mercury}

Mercury was mined in Roman times and was described by Pliny in the first century $\mathrm{AD}$ as "a poison to all things." 14a Today, although occupational exposure to mercury vapour does occur and has to be controlled, the main concern is with organic methylmercury (the most toxic form of mercury) ingested in small quantities, especially in fish.

Vast quantities of mercury are naturally present in the environment, the major source being the degassing of the earth's crust, and there are some 70 million tons in the sea. ${ }^{15} 16$ But mercury from industrial and other sources has greatly increased-as is seen from the rise in mercury concentrations in falcons' feathers (examined in Swedish museum specimens) from 2.5 ppm for 1834-1940 to over $40 \mathrm{ppm}$ for 1941-65.17 High concentrations of mercury in lakes and rivers, and hence fish and shellfish, may come from industrial waste or sometimes contamination with mercurial fungicides. Moreover, fish may be polluted with methylmercury without any pollution of the water by methylmercury - which can be synthesised from various forms of mercury by microorganisms in the sediments. It then becomes concentrated in the aquatic food chain. Normally this does not matter as the amounts 
ingested in a mixed diet are very small; but might people who eat fish containing high concentrations as a staple part of their diet be at risk in the long term?

Information about thresholds for ill effects has come especially from studies on two Japanese epidemics (at Minamata Bay and Niigata) of poisoning during 1953-60 caused by eating highly polluted fish for months or years, ${ }^{16}$ and from the large outbreak in Iraq that resulted from eating for up to two months home-made bread prepared from seed wheat treated with methylmercury fungicide. ${ }^{1819}$ The main toxic effects, which are irreversible, are (in order of severity of poisoning) paraesthesia, ataxia, dysarthria, hearing loss, coma, and death; individual susceptibility varies because of differences in the time taken to clear the mercury from the body. In the Japanese outbreaks the data on blood mercury concentrations were not entirely reliable, and in the Iraqi epidemic analyses were not done until after the sufferers had stopped eating the affected bread; so there is some uncertainty about the level at which cases of paraesthesia begin to appear. ${ }^{15} 16$

For the Iraqis developing paraesthesia the minimum daily intake of mercury might have been $28 \mu \mathrm{g} / \mathrm{kg}$ body weight-or even more. Two Swedish compulsive fish eaters are reported to have consumed daily, all through the fishing season, fish containing $6 \mathrm{ppm}$ mercuryin one case $19-20 \mu \mathrm{g} / \mathrm{kg}$ body weight-without having any suspicious symptoms. ${ }^{15}$ Again, two New Mexico adults ingested without ill effect some $50-60 \mu \mathrm{g} / \mathrm{kg}$ a day over three months from pork contaminated via methylmercury-dressed grain; three of the children, however, were severely poisoned. ${ }^{20}$

The fetus appears to be more sensitive to methylmercury according to evidence of congenital cerebral effects from Japan. ${ }^{16}$ Moreover, one baby whose mother, a member of the New Mexico family, suffered no ill effects showed neurological damage. ${ }^{21}$ More information is needed about threshold doses for the benefit of pregnant women who live near polluted waters and who have fish as a staple part of their diet.

Despite the fact that fish and shellfish concentrate methylmercury there have been no reports of poisoning from fish caught beyond the reach of industrial waste containing mercury; even fishermen eating predominantly tuna (which tends to have high concentrations) for four or five months at a time over several years have blood mercury concentrations under $174 \mathrm{nmol} / \mathrm{l}(35 \mu \mathrm{g} / \mathrm{l})$ and have shown no ill effects. ${ }^{15}$ Moreover, fish-eating populations, with a daily mercury intake usually below $5 \mu \mathrm{g} / \mathrm{kg}$ body weight but for a whole lifetime, have shown no evidence of harm.

In Britain people not occupationally exposed to mercury but eating a lot of fish with a relatively high mercury content have shown fairly low blood concentrations, in the range 50-150 $\mathrm{nmol} / \mathrm{l}(10-30 \mu \mathrm{g} / \mathrm{l})$ (higher values are found in comparable groups in, for example, Canada, Finland, and Peru). ${ }^{17}$ Inland lakes have higher pollution than the sea. The Working Party on the Monitoring of Foodstuffs for Heavy Metals has considered the matter several times and has concluded that because such small amounts of mercury have been found in the foods analysed, including fish, statutory limits are unnecessary, though they urged vigilance and continuing review. More effort needs to be made, it was concluded, to identify people living on unusual diets (which might include not only fish and shellfish but wild birds such as wood pigeons eating mercury-treated seeds): relatively few have been studied so far. There is no worry about people eating average amounts of fish; the FAO/WHO's recommended limit of $0.2 \mathrm{mg}$ methylmercury a week should not be exceeded unless a person eats about $0.5 \mathrm{~kg}$ of fish a day of average mercury content. ${ }^{17}$ Clearly particular notice should be taken of possibly vulnerable people such as pregnant women.

\section{Cadmium}

The outbreak of itai-itai (literally ouch-ouch) disease in Japan was the event that first drew attention to the environmental hazards of cadmium poisoning. ${ }^{22}$ In 1945 people living downstream from the Kamioka zinc-cadmium-lead mine began to suffer from pains in the back and legs, with fractures, decalcification, and skeletal deformation in advanced cases. Blood and kidney abnormalities, with proteinuria, and also intestinal changes were found; but the full syndrome occurred only in postmenopausal women who had had several pregnancies. The

\section{Cadmium}

Cadmium is a relatively sparse metal present with zinc and in complex ores and dispersed by natural and industrial processes throughout the environment. The refined metal is used for corrosion-resistant coatings and as a constituent of alloys. Cadmium compounds have been used as pigments; in luminous paints, antiseptics, fungicides, and plastics; and for various other purposes. Though taken up by fresh water, marine, and land plants and animals, cadmium does not usually accumulate through the food chain; but concentrations are higher in liver and kidney, which are target organs, than other meat. Zinc seems to moderate both uptake and toxicity. The average intake in the British diet (mainly from vegetables and cereals) is about $20 \mu \mathrm{g}$ a day (FAO/WHO range $57 \cdot 1-71 \cdot 4 \mu \mathrm{g}$ ). But for those smoking over 20 unfiltered cigarettes a day tobacco is the main source. ${ }^{22}$

incidence of the disease was correlated with the cadmium concentration both in the soil and in the rice, the irrigation water having become contaminated; but drinking water was also highly polluted, and wartime undernutrition may also have played a part.

The increased use of cadmium and its release into the environment in the last few decades has reinforced the concern aroused by itai-itai disease. Though not a common element, cadmium is widely distributed in nature, nearly always in association with other metals, notably zinc. Apart from the limited natural mobilisation from rocks and soil, it is released through the smelting and refining of zinc and lead ores containing it, the recovery of scrap metal, combustion of coal and oil, and disposal of sewage sludge and industrial wastes (including plastics). ${ }^{25}$

Food is the main source of cadmium intake in the general population. Vegetables, which take up cadmium from the soil, contribute the most; but the content is usually very low. People may have an aboveaverage intake through eating vegetables (chiefly leafy ones) grown on soil with a high cadmium concentration or on land fertilised with cadmium-containing sludge, or through eating contaminated shellfish in large quantities. ${ }^{22}$ Water, beverages, and inhaled air are normally minor sources; but respiration is an important route for the occupationally exposed and for heavy smokers (tobacco contains cadmium) -in fact, a greater proportion of inhaled than of ingested cadmium is absorbed. ${ }^{22-24}$ The two main target organs for long-term exposure to moderate concentrations of cadmium are the lungs and the kidneythe latter being the "critical" organ showing the earliest signs of toxicity (with $1.78 \mu \mathrm{mol}(200 \mu \mathrm{g}) / \mathrm{g}$ cadmium in the kidney as the tentatively estimated threshold). ${ }^{22-24}$

In workers exposed to fumes and dust the toxic action on both kidneys and lungs is well established. By comparison the quantities ingested over a lifetime by the general public are very small. But cadmium is a cumulative poison, for generally less is excreted than absorbed and it has a half life probably of about 30 years; so that it tends to build up in the kidneys and also liver. Even though the postulated critical concentration for kidney damage is unlikely to be reached, an association between cadmium and hypertension has been claimed. ${ }^{24}$ Experimentally cadmium is associated with hypertension, though not invariably or in all studies. Clinically, there is some suggestive evidence: for example, in one series the mean blood cadmium concentrations of untreated hypertensives were over three times those of normal people. ${ }^{26}$ Nevertheless, a review concluded that human and animal data pointed to an "interesting correlation between cadmium and hypertension," but that any assumption about cause and effect seemed unjustified. ${ }^{25}$ Carcinogenic, mutagenic, and teratogenic effects of cadmium have been found in animals but there is no firm evidence for them in man. ${ }^{24}$

The average intake of cadmium in food in Britain is low and within the FAO/WHO's provisional recommended limit of 
400-500 $\mu$ g a week (designed to prevent the kidney exceeding a concentration of $445 \mathrm{nmol} / \mathrm{g}$ ). ${ }^{22}$ But the recent government report emphasises the need for more information on people eating diets of unusual size or composition-and the need, as with other toxic elements that have no biological function, to keep exposure as low as possible.

Unusual conditions may call for special precautions, as has happened in Shipham, Somerset. Here old mine workings have given rise to high cadmium concentrations in the soil-in garden plots the average was $87 \mathrm{ppm}$ (range 2-520 ppm), compared with the UK average of 2 ppm. ${ }^{27}$ Leafy vegetables and chicken offals had high cadmium concentrations, and the inhabitants have been advised not to eat locally produced vegetables-and not to smoke. No obvious effects on health have emerged, but the results of health checks in the "control" village of North Petherton are still awaited. There is also the proviso that not many of the people have lived in Shipham for the 30 years probably needed for health effects to appear. But in fact, from the diets studied, the average weekly intake of cadmium was only 250 (range 140-520) $\mu \mathrm{g}$, the UK average being 140 (range 90-180) $\mu \mathrm{g}$; and only a few people exceeded the FAO/WHO limit. This is encouraging in view of the unusual pollution of the area.

I am grateful for helpful discussion with Dr J Facer, Department of Health and Social Security; Professor B Jarvis, British Food Manufacturing Research Association; Dr D W R Mackenzie, London School of Hygiene and Tropical Medicine; and Dr L Magos, Medical Research Council Toxicology Unit, Carshalton.

\section{References}

1 Scott PP. Food additives and contaminants. Practitioner 1979;222:648-55 2 Crampton RF, Charlesworth FA. Occurrence of natural toxins in food Br Med Bull 1975 ;31:209-13.

${ }^{3}$ Shubik P. Food additives, contaminants, and cancer. Prev Med 1980;9: 197-201.

${ }^{4}$ Lock S, Smith T. The medical risks of life. Harmondsworth: Penguin Books, 1976.

5 Austwick PKC. Mycotoxins. Br Med Bull 1975 ;31 :222-9.

${ }^{6}$ Lancaster MC, Jenkins FP, Philip J McL; Sargeant K, Sheridan A, O'Kelly J, Carneghan RBA. Toxicity association with certain samples of groundnuts [two letters]. Nature 1961 ;192:1095-7.

7 Newberne PM, Butler WH. Acute and chronic effects of aflatoxin on the liver of domestic and laboratory animals. A review. Cancer Res 1969; $29: 236-50$.

${ }^{8}$ Garner RC. Carcinogenesis by fungal products. Br Med Bull $1980 ; 36$ : 47-52.

9 World Health Organisation. Environmental health criteria 11. Mycotoxins. Geneva: WHO, 1979.

10 Steering Group on Food Surveillance, Working Party on Mycotoxins. Survey of mycotoxins in the United Kingdom. Ministry of Agriculture, Fisheries, and Food. London: HMSO, 1980.

${ }^{11}$ Krishnamachari KAVR, Bhat RV, Nagarajan V, Tilak TBG. Hepatitis due to aflatoxins. An outbreak in Western India. Lancet 1975; ; :1061-3.

12 Van Rensburg SJ, Van der Watt JJ, Purchase IFH, Pereira Coutinho L, Markham R. Primary liver cancer rate and aflatoxin intake in a high cancer area. $S$ Afr Med $\mathcal{F} 1974 ; 48: 2508 \mathrm{a}-\mathrm{d}$.

13 Jarvis B. Mycotoxins in food. In: Skinner FA, Carr JG, eds. Microbiological trends in agriculture, fisheries and food. London: Academic Press, 1975:251-67.

${ }^{14}$ Fishback H, Rodricks JV. Quoted by Jarvis. ${ }^{13}$

14apliny. Natural history 33 (6): para 32.

15 Magos L. Mercury and mercurials. Br Med Bull 1975 ;31:241-5.

${ }^{16}$ World Health Organisation. Environmental health criteria 1. Mercury. Geneva: WHO, 1976.

${ }^{17}$ Interdepartmental Working Group on Heavy Metals. Environmental mercury and man. Department of the Environment and Control Unit on Environmental Pollution, Pollution paper No 10. London: HMSO, 1976.

18 World Health Organisation. Conference on intoxication due to methylmercury-treated seed. Bull WHO 1976;53, suppl.

19 Bakir F, Damluji SF, Amin-Zaki L, et al. Methylmercury poisoning in Iraq. Science 1973;181:230-41.

${ }^{20}$ Pierce PE, Thompson JF, Likosky WH, Nickey LN, Barthel WF, Hinman AR. Alkyl mercury poisoning in humans. Report of an outbreak. $\mathcal{f} A M A$ $1972 ; 220: 1439-42$.

${ }^{21}$ Snyder RD. Congential mercury poisoning. $N$ Engl $\mathcal{F}$ Med 1971 ;284: 1014-6.

${ }^{22}$ Department of the Environment Central Directorate on Environmental Pollution. Cadmium in the environment and its significance to man. An interdepartmental report. Pollution paper No 17. London: HMSO, 1980.

${ }^{23}$ Webb M. Cadmium. Br Med Bull $1975 ; 31: 246-50$.

${ }^{24}$ Commission of the European Communities. Criteria (dose/effect relationships) for cadmium. Oxford: Pergamon Press, 1978.

${ }^{25}$ Bousquet WF. Cardiovascular and renal effects of cadmium. In: Mennear JH. Cadmium toxicity. New York: Marcel Dekker, 1976:133-49.

26 Glauser SC, Bello CT, Glauser EM. Blood cadmium levels in normotensive and untreated hypertensive humans. Lancet 1976;i:717-8.

27 Thomas JFA (Shipham Survey Committee). Soil contamination at Shipham - report on studies completed in the village and advice to residents. London: Department of the Environment, December 1980.

\section{How may epilepsy and its treatment affect a child's learning abilities?}

This complex subject is well reviewed by O'Donohoe. ${ }^{1}$ Though most children with epilepsy (between 6 and 8 per 1000 children of school age in Britain) attend normal schools, many consistently underachieve, and their teachers' reports often categorise them as inattentive, absent-minded, lacking in concentration, and sleepy. Difficult behaviour is another common complaint. There is a striking sex difference, inattentiveness and overactivity being commoner in epileptic than in non-epileptic boys, a difference not noted among girls. Most teachers and some parents tend to blame anticonvulsants for these education problems. Often they are right, especially where phenobarbitone and primidone are concerned. With the newer anticonvulsants, sedation and mental dulling are less common but, even with careful monitoring of blood concentrations, adverse effects on learning are seen. This becomes clear in some cases only in retrospect when a child finally ceases his medication and is seen to make better progress. Polypharmacy is especially likely to produce these problems. Phenytoin used over long periods seems to be associated with poorer reading skills than other drugs. An additional factor in some cases may be that teachers expect and therefore demand less of children whom they know to be taking medication, although happily the stereotype of the dull and difficult "epileptic child" has become rarer than it was.

Interruption of attention during seizures is an important cause of educational problems in some children, especially those with true petit mal, with spike-wave complexes of 3 cycles/s in the electroencephalogram and in some with "miron epilepic status" whose fluctuating performance may be correlated with clinical and electrical evidence of frequent minor attacks. Though medication is often blamed for this, the fluctuating condition of the child is unlikely to be due to drugs whose dosage is constant and whose blood concentrations vary only slightly. The EEG can give useful clues to these problems. Perceptual difficulties are common in children with epilepsy, as in children with organic brain disease in general. Reading skills were impaired in about one-fifth of children in the comprehensive Isle of Wight study by Rutter, et al. ${ }^{2}$ The reading skills of children with epilepsy attending normal schools were studied in detail by Stores and Hart $^{3}$ with special reference to generalised and focal EEG discharges and to sex. Children with persistent focal spike discharges tended to have lower reading levels than their non-epileptic matched controls, and this poor performance was largely due to those with left hemisphere focal spikes, most of whom were boys. Generalised epilepsy and subclinical seizure discharges were not associated with impaired reading skills. Boys with all forms of epilepsy had poorer reading skills than girls. Improvements in the learning difficulties of children with epilepsy will come from educating doctors in the better management of anticonvulsant medication, from newer and better drugs (the more recent recruits, carbamazepine and sodium valproate, are generally freer from sedative side effects), and from educating teachers to recognise the problems of these children. In this way appropriate help can be given and, in many cases, secondary disturbances of behaviour and personality avoided.

1 O'Donohoe NV. Epilepsies of childhood. London: Butterworths, 1979 Rutter M, Graham P, Yule W. Clinics in development medicine. No 35/36: A neuropsychiatric study in childhood. London: Spastics International and Heinemann, 1970.
Stores G, Hart Dev Med Child Neurol 1976;18:705-16. 